\title{
Ausências e presenças na Revista Brasileira de Poesia $(1947-1956)^{1}$
}

\section{Carlos SPEck PEREIRA* JEFERSON CANDIDO**}

\section{Resumo}

O artigo apresenta as reincidências e os apagamentos no espaço da Revista Brasileira de Poesia (1947-1956). Ainda que editada por poetas, observa-se na revista a passagem de linhagens poéticas díspares e a formação de um grupo heterogêneo e entrelaçado por divergências estéticas. A respeito dos poetas editores do periódico, estreantes no período marcado pelo segundo pós-guerra, o estudo revisita a oposição (instaurada por eles e pela crítica historiográfica) entre prolongamento versus ruptura para com o Modernismo de $22 \mathrm{e}$, em vez de resolvê-la, procura recuperá-la como tensão.

Palavras-chave: Modernismo. Poesia moderna. Revista literária. Poetas de 45.

História, não da literatura, mas do rumor lateral, da escrita cotidiana e tão rapidamente apagada que nunca adquire o status da obra ou que imediatamente o perde: análise das subliteraturas, dos almanaques, das revistas e dos jornais, dos sucessos fugidios, dos autores inconfessáveis. (FOUCAULT, 1997, p. 157)

1 O presente artigo resulta do primeiro capítulo do Trabalho de Conclusão de Curso em Letras-Português desenvolvido na Universidade Federal de Santa Catarina. Ver PEREIRA, 2020.

* Mestrando em Literatura no Programa de Pós-Graduação em Literatura da Universidade Federal de Santa Catarina/UFSC, Florianópolis, Santa Catarina, Brasil. Pesquisador do Núcleo de Estudos Literários \& Culturais (NELIC/UFSC). Bolsista do Programa UNIEDU/FUMDES Pós-Graduação.

E-mail: carlosspeckpereira@gmail.com Orcid iD: https://orcid.org/0000-0003-4113-2117

** Doutor em Literatura pelo Programa de Pós-Graduação em Literatura da Universidade Federal de Santa Catarina/UFSC, Florianópolis, Santa Catarina, Brasil. Pesquisador do Núcleo de Estudos Literários \& Culturais (NELIC/UFSC).

E-mail: jefcandido@gmail.com Orcid iD: https://orcid.org/0000-0003-0874-6512 
Através de uma revista é possível ler o registro de uma "unidade discursiva", tal como comenta Michel Foucault (1997) em A arqueologia do saber, ou seja, ler a "emergência" do discurso, que não se dá pela "coerência de conceitos" tanto quanto se revela na dispersão, na sucessividade, na reincidência, ou, ainda, naquilo que resta do/no tempo e resiste: "[...] não buscaríamos mais, então, uma arquitetura de conceitos suficientemente gerais e abstratos para explicar todos os outros e introduzi-los no mesmo edifício dedutivo; tentaríamos analisar o jogo de seus aparecimentos e de sua dispersão" (FOUCAULT, 1997, p. 40).

O estudo sobre os poetas de 45 parece facilitar essa espécie de movimento de análise. Agrupamento de poetas que fez parte não de uma geração marcada por manifestos aglutinadores, tampouco por coerências evidentes, mas por transições, anacronismos e - mais precisamente - por revistas, como a Revista Brasileira de Poesia.

A Revista Brasileira de Poesia (doravante RBP) teve sete números, editadosentre 1947e 1956 em São Paulo ${ }^{1}$. Veiculandopreponderantemente ensaios, resenhas e poemas, além de notas biográficas e relatórios do Clube de Poesia de São Paulo e do I Congresso de Poesia de São Paulo ${ }^{2}$ ocorrido em 1948, a revista tinha por eixo norteador a temática da poesia, desde a sua manifestação propriamente dita na publicação de poemas ao ensaísmo e à crítica literária.

Em seu primeiro número, a folha de rosto apresenta ao leitor os seus editores e uma espécie de divisão funcional: Péricles Eugênio da Silva Ramos (diretor responsável), Domingos Carvalho da Silva (secretário de redação), Geraldo Vidigal (subsecretário de redação), João

1 As edições foram publicadas com relativa periodicidade até o quinto número, sendo as duas edições restantes postergadas para os últimos três anos de "existência", conforme relação a seguir: v. 1, n. 1, dez. 1947; v. 1, n. 2, abr. 1948; v. 1, n. 3, ago. 1948; v. 1, n. 4, fev. 1949; v. 2, n. 5, set. 1949; v. 2, n. 6, set. 1953; v. 2, n. 7, abr. 1956.

2 O evento foi promovido pela Revista Brasileira de Poesia entre os dias 29 de abril e 2 de maio de 1948 e congregou poetas e estudiosos de poesia para a discussão de temas tais como as "causas e consequências da escola modernista" e os "aspectos atuais da poesia brasileira e da crítica poética”. 
Accioli (subsecretário de redação) e Carlos Burlamaqui Köpke (diretor administrativo). Apesar dessa divisão diluir-se a partir do segundo número do periódico na denominação "Conselho Diretor", que abarca os integrantes mencionados, ela permite reflexões acerca do papel de cada um desses membros, que, vale lembrar, são, em grande parte, poetas à época bastante jovens e que integraram a página (diminuta) dedicada à poesia da "Geração de 45" (PICCHIO, 1997).

Através de uma visão de conjunto proporcionada pela leitura minuciosa de toda a revista e da catalogação de cada unidade textual presente nas suas páginas, seguida de um processo informatizado de cruzamento desses dados, é possível observar o registro de determinadas ocorrências e atestar o grau de sua repetição. ${ }^{3}$

De acordo com a indexação, nota-se que os gêneros do discurso mais frequentes na RBP são: o ensaio, apresentando 67 textos; a resenha, com 39 textos; e o poema, com $30^{4}$. A grande maioria dos textos, mesmo os não poéticos, se relaciona à temática da poesia, seja no campo da crítica literária, seja na teoria, ou até mesmo através de informes da vida literária (19 textos), como viagens de poetas estrangeiros ao Brasil, falecimento de poetas brasileiros ou divulgação do I Congresso de Poesia de São Paulo, promovido e organizado pelos editores da RBP, e de suas consequências (como a conformação do Clube de Poesia de São Paulo). Entre os autores que assinam os textos figuram principalmente poetas e críticos de poesia,

A revista foi indexada na base de dados Periodismo Literário e Cultural, mantida pelo Núcleo de Estudos Literários \& Culturais (NELIC) da Universidade Federal de Santa Catarina (UFSC). Tal base funciona como um agregador de fichas eletrônicas de leitura, permitindo, assim, não apenas a geração de estatísticas da revista em si, mas, também, o cruzamento de dados entre as diversas revistas já indexadas a partir de campos de busca como autores-colaboradores, tipos de texto, assuntos, palavras-chave, etc.

4 Há maior concentração de poemas nos primeiros cinco números da revista, ao contrário dos números 6 e 7. Nesses, a poesia propriamente dita — que até a quinta edição era constituída pela apresentação de poemas de mais ou menos cinco poetas por volume - , reduz-se à publicação de poemas traduzidos de Stephen Spender (no número 6) e de Dylan Thomas (no número 7), o que dá ainda mais espaço na RBP para a transcrição de conferências proferidas nos cursos de poética promovidos pelo Clube de Poesia de São Paulo. 
com destaque para os integrantes do corpo editor, a saber, Domingos Carvalho da Silva, com 21 textos publicados; Carlos Burlamaqui Köpke, 17; Péricles Eugênio da Silva Ramos, 14; Mário da Silva Brito, 10; e Geraldo Vidigal, com cinco textos.

A partir de um repertório de palavras-chave contido no sistema de indexação da base, podemos levantar a frequência de determinados assuntos no corpo da revista. Esse repertório é limitado, mas isso se justifica para que seja assegurada a possibilidade de cruzamento e posterior diálogo entre os dados da base. Por exemplo, é evidente que a palavra "Formalismo" ao longo da história da Teoria da Literatura e da crítica literária assumiu significados bem específicos e, portanto, marcados historicamente, porém, é interessante para o pesquisador que consulta a base a condição de analisar, num só relatório de indexação, a flutuação que a palavra foi assumindo ao longo de certo conjunto de textos. Portanto, na falta justificada de palavras como "Rigor", "Ritmo", ou "Forma fixa”, apenas para citar exemplos de um só campo semântico, no momento de escolha de palavras-chave adequadas aos textos optamos pelo uso concentrado de itens contidos no repertório do sistema. Por conseguinte, vemos saltar aos olhos a frequência das seguintes palavras-chave: Poesia (referente a 131 textos), Geração de 45 (53), Crítica (43), Eventos (18), Formalismo (19), Informes (31), Modernismo (31), Métrica (13), São Paulo (8), Tradição (12), Biografia (12), Lirismo (8) e Morte (11).

Haja vista a expressiva retomada da tradição, da métrica, do lirismo e de uma espécie de formalismo via de regra acompanhado do discurso em torno dos valores estéticos modernistas, é importante relembrar da dissertação primeira (e talvez única) centrada no estudo da RBP, de Alves (1979), pois ela evidencia o debate que se realiza na revista entre o "afastamento" e o "contato com o movimento modernista" (p. 1) brasileiro, presente na discussão acerca da sensibilidade poética em fase de desponte nos idos de 1940. Conforme Nunes (2007, p. 142-143), essa sensibilidade é uma sensibilidade híbrida, que testemunha a

[...] recepção, nessa época, dos romances, dos escritos filosóficos e dos ensaios literários de Jean-Paul Sartre; junto, chegavam-nos as obras de 
Albert Camus, além das traduções de Kierkegaard e de Kafka, partes da mesma constelação do pensamento existencial formada na França, concorrentes, entre nós, do marxismo e do neotomismo dos intelectuais católicos. Das vanguardas da primeira metade do século, de onde saíram os poetas lidos pelos nossos modernistas, a exemplo de Apollinaire, Max Jacob, Pierre Reverdy, Picabia, Blaise Cendrars, André Breton, ainda recebíamos os ecos do último e resistente surrealismo. Mas nessa década de 1940, os modernistas, sobretudo Mário de Andrade, Oswald de Andrade, Carlos Drummond de Andrade, Murilo Mendes, Jorge de Lima e, por extensão, Cecília Meireles, já tinham sido lidos pelos seus sucessores da nova geração de que eram contemporâneos e que agora entravam em contato com Paul Valéry e Rilke, descobriam Fernando Pessoa e familiarizavam-se com os hispânicos García Lorca, Jorge Guillén e Pablo Neruda. Essas mesmas fontes também não deixaram de fecundar as obras já amadurecidas e prósperas de um Drummond e de um Murilo Mendes, enquanto os novos abriam as sendas inexploradas da moderna poesia em língua inglesa, principalmente daquela receptiva ao simbolismo francês, como a que seguiu T. S. Eliot, então pela primeira vez traduzido no Brasil. Reabriram igualmente antigos veios estancados de nossa tradição, como o próprio Simbolismo, que o dominante prestígio dos parnasianos havia neutralizado e que retomaram das nascentes em Baudelaire, Rimbaud e Mallarmé. Mas já então num clima de geral refluxo das linhas tradicionais, o próprio Parnasianismo, cavalo de batalha do movimento modernista, voltava à tona do interesse intelectual, conforme atestam, corroborando o cuidado da forma entre os jovens poetas, a republicação do Tratado de versificação, de Olavo Bilac e Guimarães Passos, e o aparecimento de biografias do primeiro, consagrada estrela do Parnaso.

De fato, a revista possibilita a visão, num mesmo volume, de um embate de crítica no qual, de um lado, há a atenção para o que resta do modernismo como herança ou "prolongamento", como defende Péricles Eugênio da Silva Ramos em "O neo-modernismo" e, de outro, a alimentação da ideia de ruptura com o movimento de 1922, fortemente endossada pelo poeta e crítico literário Domingos Carvalho da Silva, o secretário de redação - "Há uma nova poesia no Brasil”, conferência sua 
proferida no I Congresso de Poesia de São Paulo e publicada na seção "Arquivo" da revista, é exemplo expressivo dessa espécie de ideal de ruptura com a estética modernista.

A distinção provocada por este embate crítico ou "luta de famílias" extrapola o âmbito da RBP. O referido embate dicotômico entre a sensibilidade poética como prolongamento ou ruptura do modernismo não se limita tampouco a outros meios de difusão das manifestações da crítica da mesma época, mas atravessa o tempo e chega a trabalhos acadêmicos posteriores. A dissertação de Alves (1979) acerca da RBP se voltava, em primeiro lugar, para “[...] a fixação de pontos de afastamento e de contato com o movimento modernista, bem como para o questionamento de sua posição no processo de desenvolvimento de nossa literatura”. Para esse empreendimento, a pesquisadora destaca vozes que se enunciam na revista e as classifica conforme o "lado" da disputa: prolongamento versus ruptura com o modernismo. Entretanto, em determinado momento, em vez de apenas dar a ver a tensão entre as duas correntes da crítica, a autora também assume o seu próprio lado no debate:

De um modo geral, porém, podemos dizer que o Pós-modernismo é compreendido como um elo do processo inovador instituído pelos poetas de 22, uma exploração em profundidade de várias de suas premissas, uma oposição por aquilo que representa de superação e de inovação mas não um rompimento completo e definitivo com o Modernismo. (ALVES, 1979, p. 10)

A autora é enfática ao avaliar a "ineficiência" dos projetos estéticos presentes nas manifestações críticas dentro do âmbito da revista em relação à realização efetiva da poesia daquele conjunto de poetas, ineficiência que se projetaria na falta de correspondência entre o que é teorizado pelos críticos-poetas e o que esses poetas-críticos produzem em matéria de poesia.

Mais que deter-se nessa questão, o presente estudo busca ler a revista para além da perspectiva de Alves (1979), isto é, sem procurar por uma linhagem específica, posto que a RBP não se configura (apesar de 
tudo) como um órgão representativo da Geração de 45. A RBP é antes um projeto que a representação, uma vez que ela pode ser vista como exemplo concentrado do que Camilo (2020), a respeito da poesia do período do segundo pós-guerra, chamou de "encruzilhada da lírica moderna".

Olhares atentos diante da capa austera da RBP não deduziriam que a imagem que os olha de volta reúne atrás de si, logo no índice, a participação de personalidades significativas para outras revistas literárias "mais despojadas", como a Joaquim e a Edifício, caso, por exemplo, de Dalton Trevisan, editor da Joaquim e representante da RBP no Paraná, ou de Bueno de Rivera, poeta mineiro publicado nesta e na Edifício. ${ }^{5}$ Além dos escritores mencionados, à época contemporâneos, uma primeira impressão de sua capa também não faria deduzir que a revista é espaço de publicação de personas sobremaneira destacadas no cenário da poesia brasileira moderna, ou, mais especificamente, modernista, vale dizer, daquilo que já havia se tornado tradição antes mesmo de a revista vir a ser o que ela era: Oswald de Andrade, Manuel Bandeira ${ }^{6}$, Sérgio Milliet e Menotti del Picchia são amplamente citados e/ou autores de conferências transcritas ou ensaios.

Aqueles olhos, mesmo os que detinham em seu passado leituras em torno do que fora a poesia dos anos 1940, tampouco pensariam encontrar atrás dessa capa austera publicações de Haroldo e Augusto de Campos, antes de qualquer Noigandres, ao lado de ensaios e poemas de Domingos Carvalho da Silva, Péricles Eugênio da Silva Ramos ou de Bueno de Rivera, três nomes que mais tarde integrarão uma só e diminuta página da história da literatura brasileira chamada de Geração de 45 (que, aliás, seria fortemente posta em discussão por Sérgio Buarque de Holanda, crítico arguto dos poetas de 45 e autor de artigo publicado no primeiro número da RBP, além de amplamente citado nela). Ou, ainda, num só volume, também encontrar traduções de Dora Ferreira da Silva antes de suas instigantes Diálogo (1955-1964) e Cavalo Azul (1965-1989), bem como

A partir do número 5 da RBP, Bueno de Rivera passará a fazer parte de seu conselho consultivo.

6 Ver PEREIRA; CAMARGO, 2019. 
a poesia de Décio Pignatari em estreia. Poéticas que mais tarde tomariam caminhos particulares e se afinariam a linhagens outras, mais ou menos divergentes do(s) projeto(s) estético(s) que se formulam na RBP.

Através dos relatórios referidos foi possível atestar a expressiva citação de personalidades significativas para a construção da chamada tradição modernista: Mário de Andrade é um nome verificado em 19 textos até a derradeira edição; outra figura importante do modernismo paulista bastante citado é Oswald de Andrade, em 20 textos - Oswald, inclusive, participou do I Congresso de Poesia de São Paulo e esteve presente em algumas de suas discussões mais acaloradas: sabe-se disso porque todo o desenvolvimento do evento é amplamente divulgado nas páginas da seção "Noticiário" da RBP n. 3 (de 1948), escrita com o aspecto de ata.

É claro que números - neste caso, os números de um índice construído através de um processo de indexação da RBP - encobrem conteúdos muitas vezes díspares sobre uma mesma matéria. Mas, através desses números, conseguimos uma visão de conjunto, ampliada, e somos capazes de enxergar algumas arestas. Através do número e de sua quantidade, expressiva ou não, vê-se uma presença. Porém, é com a medida da ausência que nos damos conta de que, em matéria de revista, a presença é fruto de escolhas. Assim, podemos enxergar o fato de que Oswald de Andrade é um dos poetas mais citados ao longo de toda a RBP e, ao mesmo tempo, perceber que ele não é autor de nenhum dos versos ou da crítica enunciada ao longo dessa mesma revista.

Vale lembrar que antes de sua Revista de Antropofagia, lá na década de 1920, essa ausência-presença de Oswald também acontecera nas páginas de revistas modernistas do círculo mais "badalado" do modernismo paulista, carioca e mineiro, sendo pouquíssimo publicado nesses veículos da chamada fase "heroica" do movimento. Marques (2013, p. 92) levanta a hipótese "de que seu temperamento corrosivo e blagueur [...] não se adequasse espontaneamente aos espaços cautelosos de "prosa raciocinadora' em que se haviam transformado as revistas”.

Nos anos de publicação da RBP, não só no mesmo tempo como no mesmo espaço de atuação, não faltava a Oswald de Andrade texto (nem contexto) para ser publicado, já que participou ativamente do I Congresso de Poesia de São Paulo (1948) e, em seguida, com a consolidação do Clube de Poesia, apresentou conferência em cursos de poética promovidos 
pelo Clube em 1949. Oswald, apesar de sempre presente/ausente, era um antagonista: prova disso são seus comentários contemporâneos à publicação da RBP escritos para a sua coluna “Telefonema”, em que alfineta chistosamente e denuncia o tom bacharelesco e a expressão questionável do grupo de 45 (ANDRADE, 2007).

É curioso observar que no terceiro número da revista, o primeiro após o I Congresso de Poesia de São Paulo, são apresentadas várias transcrições de conferências proferidas no evento, bem como todo o relatório de seu andamento. Pode-se afirmar que é um número inteiro dedicado ao congresso. Entretanto, mesmo que o evento preencha a parte "nobre" da edição e toda a seção "Noticiário", não são publicadas as comunicações de pessoas de destaque como a do próprio Oswald de Andrade, proferida na quinta sessão do congresso, nem a de Antonio Candido - que foi a conferência de abertura (!) -, provavelmente pelo conteúdo que não agradara aos componentes do grupo "de 45" (o rótulo “Geração de 45", vale lembrar, foi cunhado por Domingos Carvalho da Silva na mesma ocasião). É o que nos revela Vinícius Dantas, organizador dos Textos de intervenção de Antonio Candido, entre os quais se encontra, publicado pela primeira vez, o discurso de abertura do congresso. Em nota, Dantas comenta:

Principal representante da crítica nova, Antonio Candido foi convidado para abrir o congresso que consagraria as tendências recentes da poesia brasileira, aquelas ligadas à geração que se convencionou chamar de 45. Em artigos anteriores como "Sobre poesia", "Duas notas de poética”, "Ordem e Progresso na poesia”, ele já assinalava que essa produção se nutria do desejo de se diferenciar do Modernismo, embora não imaginasse as raias de campanha difamatória a que chegaria a política literária dos novos. $\mathrm{O}$ orador responde aqui ao maniqueísmo dessa confrontação um tanto forjada, que mascara os veios de continuidade que ligavam a Geração de 45 à experiência imediatamente anterior. $\mathrm{O}$ discurso parece ter decepcionado os poetas, que, ciosos arquivistas dos próprios feitos, nunca o divulgaram. (CANDIDO, 2002, p. 167) 
No discurso, Candido atentava para certa esterilidade de dicotomias. Contudo, a fim de resolver especificamente a dicotomia relacionada ao prolongamento do modernismo na extensão da nova geração, propõe que, em vez de conflito geracional, o que se passava entre a poesia de 22 e a poesia de meados de 40 era, na verdade, conflito de constantes poéticas, afirmando que os jovens poetas

Perceberam cedo, lendo os maiores, que, por exemplo, um anjo olhando no binóculo o som de um telefone de que nascem flores é qualquer coisa de bizarro, no sentido correto e no sentido galicista da palavra. E que, portanto, o leitor se sentirá provavelmente envolvido por um sentimento de mistério e fantasmagoria, atrás do qual ele, poeta, pode ocultar preguiça mental e incapacidade de pesquisa. Daí a falta de esforço para renovar o vocabulário herdado e mecanização das conotações poéticas. Mas - e aqui tocamos o ponto capital - com que intuito buscam semelhante convenção? Com o intuito já assinalado de criar a tal atmosfera, de alargar infinitamente o eco e o significado dos versos. Por isso a acromegalia estética de que padecem não raro. Os poetas atuais se conformam cada vez menos em ver, num sabiá, um sabiá como fez Gonçalves Dias. Em cada pássaro farejam, pelo menos, a Pomba, o Mensageiro, o Espírito da Poesia, e a sua namorada os faz comunicar telepaticamente com o infinito. (CANDIDO, 2002, p. 163)

Então, o crítico cita uma estrofe de João Cabral de Melo Neto na qual se verificaria "o típico" exemplo da nova "geração", a fuga do concreto na "dose máxima de abstração", extraída de $O$ engenheiro: "Surpresa do encontro / com o fantasma / na praia; / camisa branca, / corpo diáfano, / funções tranquilas / no banho de sol."

Porém, vale notar que logo depois deste livro, entre 1946 e 1947, João Cabral escreve Psicologia da composição, trazendo a flor de volta à sua palavra: "Poesia, te escrevia: / flor! conhecendo / que és fezes. Fezes / como qualquer, // gerando cogumelos / (raros, frágeis cogu- / melos) no úmido / calor de nossa boca”. Apesar do apontamento a Cabral soar um tanto pejorativo, é importante mencionar o fato de que Candido foi um dos poucos críticos paulistas que souberam enxergar a magnitude do poeta desde a sua fase de estreia, conforme as palavras de Silva (1948, p. 79-80). 
Mas além de o texto de abertura do congresso não ser publicado, a RBP apresenta, nesse mesmo número 3, outro texto de Antonio Candido (1948, p. 19-22) - um texto que destacamos, justamente, por não ter absolutamente nenhuma relação com o evento ("Notas sobre dois aspectos de Ezra Pound"), posto que os textos vizinhos são todos transcrições de teses proferidas na ocasião.

A questão geracional, no sentido mais cronológico do termo, não pode ser a motivação para as referidas faltas: tanto no caso de Oswald de Andrade - já que Menotti del Picchia, contemporâneo dos modernistas de 22, teve a sua conferência publicada nas páginas daquele número -, quanto no de Antonio Candido, pois não é excessivo lembrar que o autor nasceu em 1918, tendo, em 1948, somente trinta anos de idade. Porém, é provável que seja a questão geracional no seu sentido mais estrito - neste caso, o sentido que congrega os poetas e editores Péricles Eugênio da Silva Ramos, Domingos Carvalho da Silva, dentre outros favoráveis à aceitação de um grupo em formação -, o que regeria e manejaria a publicação dos discursos e, por extensão, dos gestos de edição que lhes convinham.

Voltando à inegável presença da tradição modernista no ideário da RBP, verifica-se que Carlos Drummond de Andrade é mencionado em 22 textos e Cecília Meireles em 18. Ambos os poetas, ao lado de Murilo Mendes (citado 12 vezes), ficam um tanto de fora da tensão instaurada contra-ou-a-favor da "influência" do Modernismo de 22 no ideário do grupo de 45. Lembremos que João Cabral de Melo Neto (citado em 17 ocasiões e com traduções de poetas catalães), no famoso conjunto de artigos publicados no Diário Carioca em 1952 sobre a Geração de 45, fala da filiação (in)voluntária dos poetas mais jovens a poéticas de autores que aproveitaram o "terreno" poético renovado após os primeiros ventos modernistas (MELO NETO, 2008); Domingos Carvalho da Silva, por sua vez, acompanhará a publicação de novos livros de Cecília Meireles e os comentará nas páginas de "Bibliografia", a seção de resenhas da revista, atentando para o que resta de Viagem nas manifestações poéticas da escritora (seus comentários à poeta datam de 1949 e 1953, números 5 e 6 da revista, respectivamente). 
Assumindo não um lado naquela disputa entre filiações e vanguarda, mas a própria tensão enquanto potência de enunciado, em movimento pendular sem eixo - a evocação dos modernistas de 22 ora como laço de parentesco geracional, ora como história diante da qual se cria ruptura - conseguimos ver, através da presença de certos nomes da tradição moderna, outros lugares: vazios que permanecem em falta, ou, melhor, omitidos por aquelas vozes da RBP, que fazem coro ao passarinho de Mário e citam Oswald em demasia sem publicá-lo.

Tomar um lado nessa disputa seria, de um lado, tomar para si Oswald de Andrade e enaltecer a sua Revista de Antropofagia como a publicação paulista mais brasileira das revistas modernistas (CAMPOS, 1975), como esta tomou para si Macunaíma e, junto de Oswald, entoar a canção que, modernamente, acontece de tudo menos "acontece o soneto" (ANDRADE, 2011, p. 172). Ou, o avesso: seguir os passos da intenção de Péricles Eugênio da Silva Ramos e de Carlos Burlamaqui Köpke e a sua revalorização de "um certo" Mário de Andrade lido em suas óticas (o que, para muitos, pode significar uma oposição com a primeira alternativa) e, em outra medida, também opor-se à movimentação do tempo e de seus poetas, que se movem - e que leem - a partir de um determinado contexto.

A revista literária é uma forma da crítica e, no entanto, estabelece com ela relações bastante tensas. Fundamentalmente hierárquica já que pressupõe o julgamento universal, a crítica oferece totalidades estratificadas que impõem conexões reguladas ou mesmo controladas entre si por uma comunidade de especialistas. (ANTELO, 1997, p. 5)

8 É característica da Revista de Antropofagia a ridicularização de certos pares modernistas, como Mário de Andrade, principalmente. Maria Eugênia Boaventura constata, inclusive, que "pode-se ordenar os ataques ao escritor em três partes: à pessoa do escritor, à sua obra e à sua atuação ao Modernismo" (1985, p. 34). De certa maneira, isso se transforma a partir do momento da publicação de Macunaíma, naquele mesmo ano de 1928. Talvez pela razão de ter sido Mário de Andrade motivo de piada dos antropófagos, além de ter sido considerado por eles como mero "copista", "padrasto" de Macunaíma, o gesto dos antropófagos para com a obra é de reivindicação. 
Tomar a própria tensão como "lado" na disputa e ignorar as perguntas do coração, mas não as dos olhos, que não perguntam nada, não deixa de ser a admissão de uma linha (poética?) não reta nem evolutiva, mas enovelada e de diversas pontas, cujas cores teimam, às vezes, em se sobreporem. Um novelo tal qual um domínio de enunciado, resume Foucault (1997), que se consubstancia pela relação do sujeito com um inexato campo a ser associado. No caso de uma revista, pela relação interna do tempo com seu escoar, retido periodicamente. Repetição, diferenciação, mas também teimosias e adjacências.

Absences and presences in Revista Brasileira de Poesia (1947-1956)

\section{AbSTRACT}

The article shows the presences and absences in Revista Brasileira de Poesia (1947-1956). Although edited by poets, it is possible to observe in the magazine the passage of disparate poetic lineages and the formation of a heterogeneous group, intertwined by aesthetic divergences. Regarding the poets who edited the journal, who were new to the period marked by the second post-war, the study revisits the opposition (established by them and by historiographical criticism) between prolongation versus rupture with the Modernism of 22 and, instead of solving it , the study seeks to recover it as tension.

KeYwords: Modernism. Modern Poetry. Literary Magazine. Poets of 45.

Ausencias y presencias en la Revista Brasileira de Poesia (1947-1956)

\section{RESUMEN}

El artículo presenta las recurrencias y apagones en el espacio de la Revista Brasileira de Poesia (1947-1956). Aunque era editada por poetas, en la revista se observa el paso de linajes poéticos dispares y la formación de un grupo heterogéneo, entrelazados por divergencias estéticas. En cuanto a los poetas editores de la revista, nóveles en el período marcado por la segunda posguerra, el estudio revisa la oposición (establecida por ellos y por la crítica historiográfica) 
entre prolongación versus ruptura con el Modernismo del 22 y, en lugar de resolverla, busca recuperarla como tensión.

Palabras Clave: Modernismo. Poesía moderna. Revista literaria. Poetas del 45.

\section{REFERÊNCIAS}

ALVES, Maria Marcelita Pereira. Revista Brasileira de Poesia: periódico pósmodernista. 1979. 141 f. Orientador: José Aderaldo Castello. Dissertação (Mestrado em Literatura Brasileira) - Faculdade de Filosofia, Letras e Ciências Humanas, Universidade de São Paulo, São Paulo, 1979.

ANDRADE, Oswald de. Novas dimensões da poesia. In: BOAVENTURA, M. E. (org.). Estética e política. 2. ed. São Paulo: Globo, 2011.p. 156-174.

ANDRADE, Oswald de. Telefonema. 2. ed. São Paulo: Globo, 2007.

ANTELO, Raúl. As revistas literárias brasileiras. Boletim de Pesquisa NELIC, Florianópolis, v. 1, n. 2, p. 3-11, 1997.

BOAVENTURA, Maria Eugênia. A vanguarda antropofágica. São Paulo: Ática, 1985.

CAMILO, Vagner. A modernidade entre tapumes: da poesia social à inflexão neoclássica na lírica brasileira moderna. Cotia: Ateliê Editorial, 2020.

CAMPOS, Augusto de. Revistas re-vistas: os antropófagos. Revista de Antropofagia. 1a e 2a "Dentições" --1928-1929. Edição fac-similar. São Paulo: Círculo do Livro, 1975. p. 5-17.

CANDIDO, Antonio. Discurso num congresso de poetas. In: DANTAS, V. Textos de intervenção. São Paulo: Editora 34, 2002. p. 159-167.

CANDIDO, Antonio. Notas sobre dois aspectos de Ezra Pound. Revista Brasileira de Poesia, v. 1, n. 3, p. 19-22, ago. 1948.

FOUCAULT, Michel. A arqueologia do saber. 5. ed. Tradução Luiz Felipe B. Neves. Rio de Janeiro: Forense Universitária, 1997.

MARQUES, Ivan. Modernismo em revista: estética e ideologia nos periódicos dos anos 1920. Rio de Janeiro: Casa da Palavra, 2013. 
MELO NETO, João Cabral. A Geração de 45. In: SECCHIN, Antonio Carlos. Poesia completa e prosa. 2. ed. Rio de Janeiro: Nova Aguilar, 2008. p. 719-732.

NUNES, Benedito. A 'Geração de 45' e João Cabral. In: MÜLLER, A. João Cabral: a máquina do poema. Brasília: Editora UNB, 2007. p. 139-173.

PEREIRA, Carlos Speck. Abrir uma revista pelo seu verso: um itinerário através da Revista Brasileira de Poesia. 2020. 155 f. Orientadora: Maria Lucia de Barros Camargo. Monografia (Trabalho de Conclusão de Curso em Letras) Universidade Federal de Santa Catarina, Florianópolis, 2020.

PEREIRA, Carlos Speck; CAMARGO, Maria Lucia de Barros. Gilda e Candido: leituras sobre Manuel Bandeira na Revista Brasileira de Poesia e depois. Boletim de Pesquisa NELIC, v. 19, n. 30, p. 46-55, 2019.

PICCHIO, Luciana Stegagno. História da literatura brasileira. Rio de Janeiro: Nova Aguilar, 1997.

SILVA, Domingos Carvalho da. Psicologia da composição. Revista Brasileira de Poesia, São Paulo, v. 1, n. 2, p. 79-80, 1948.

Submetido em 29de maio de 2021

Aceito em 21 de junho de 2021

Publicado em 19 de setembro de 2021 